\title{
Research on Mass Sports Culture and Mass Sports Development in Yan'an
}

\author{
Bao-rong CHANG ${ }^{1, a}$, Li ZHAO ${ }^{2, b}$, Yue LIU ${ }^{3, c}$, Guang-shuai LI, ${ }^{4, d}$ \\ College of Physical Education, Yan'an University, Yan'an 716000, China \\ abr0123@sohu.com
}

Keywords: Mass sports culture; mass sports; Yanan period

\begin{abstract}
Using literature and other methods. This paper studies the conception, historical background, environment, cognition and practice of mass sports culture in Yanan period and the course of development of mass sports in Yanan period, and explores the great influence and significance of Yanan period mass sports culture and mass sports development on revolutionary war.
\end{abstract}

\section{The concept and historical background of mass sports culture in Yanan period}

1.1 Concept definition

"Sports Dictionary" of the definition of sports: "According to the human physiology, psychological development law, specialized physical activity as the basic means to enhance physical fitness, the development of human movement capacity, improve people's quality of life of a purposeful and valuable Of social activities. "He believes that the physical function of the body is to keep fit. Sports culture has the essential characteristics of sports, but also has the cultural properties. Sports are social and cultural areas, and a social, political, economic, military and other closely linked, subject to and serve the needs of mankind. In different historical periods, sports will complete its different historical missions. Wu Pengsen in the "humanities and social science foundation" elaborated The spirit of physical culture and the pursuit of physical and mental harmony. He believes that sports is the product of the development of human body movement, is outside the material life of mankind and the pursuit of the harmonious development of physical and mental practice, is in the self-consciousness under the control of the movement as a form and means to pursue the comprehensive development of physical and mental activities. So it has a wide range of spiritual connotation beyond material utility, the social connotation of individual value, and the systematic connotation of decentralized state. Basic cultural means is the basic means of physical movement, the pursuit of a comprehensive and harmonious development. Above we can think that sports is a combination of social behavior and cultural phenomena. Sports culture has its own unique value in the development and progress of human civilization. Especially in the emotional and spiritual aspects, subtle influence on our outlook on life values.

1.2 The historical environment of mass sports culture in yan'an period

During the Yanan period, when the Chinese Communist Party led the army and the people in the war of resistance against Japanese aggression, the face of the Japanese invaders from the past eroded to devour China's territorial political policy and military attack, the Chinese nation and its dangerous external environment has reached a critical moment of life and death. At this time, the Kuomintang adopted the policy of "stabbing foreigners into the country," and pursued the military clashes and economic blockade against the Chinese people under the leadership of the Communist Party of China, which was intended to stifle the Chinese Communist Party in the red cradle. In such an extremely difficult condition, the Chinese people led by the Chinese Communist Party still achieved new achievements in politics, economy, culture and society, and built Yan'an, a povertystricken country at that time, as a model anti-Japanese base in the country and laid a solid foundation for the development of sports undertakings. Good foundation. In the political, through the implementation of the three-three system, streamlining and other new initiatives to promote the Yanan period, the construction of democratic politics, the creation of a democratic, legal, standardized new government. Economically, a new democratic economic system in which co- 
operative production is organized in the form of public ownership and coexistence of other economic sectors is adopted to realize the new economic relations of public-private cooperation. Chairman Mao issued the "hands-on, abundance of food," the general mobilization as an opportunity to carry out large-scale production and military campaign, and strive to develop the economy and improve people's living standards. Culture, the establishment of the dominant position of the new democratic culture at the same time put forward the construction of "national, scientific, popular, anti-imperialist and anti-feudal culture", the creation and development of kindergarten, primary, secondary, university and other forms of school education system, System, so that the military and civilian political and ideological consciousness and cultural level has been improved for the cause of China's revolution and build a number of outstanding talents. Establish a sense of democracy from the officers and men to the masses of all people, the use of new culture to influence the local customs to make it fit the overall situation of the war, to build a good social order, so that the spirit and social morale and a new look. Yan'an period of innovation on the social stability and development play an important role in promoting the various undertakings to create a good social environment, effectively stimulated the creation of the majority of the main social vitality. The Shaanxi-Gansu-Ningxia Border Region is known as the "Anti-Japanese Fortress" and the "Democracy Model." The famous American scholar Professor Fei Zhengqing wrote that Yan'an is a place where people want to go, sunny and pleasant. In the harmony, equality, freedom of Yan'an, political democracy for the popularization and development of Yan'an sports provided a prerequisite and possible, and laid a solid mass foundation.

\section{The understanding and practice of mass sports culture by the leaders of the Party Central Committee in Yan'an period}

In October 1938, Mao Zedong pointed out in his essay "On the New Stage": "The great war of resistance must have a great campaign of anti-Japanese warfare." "Under the principle of war, all cultural and educational undertakings should make it Suitable for the needs of the war. "At that time the main task of sports is closely around the war and serve the war, sports and revolutionary struggle are inseparable. Mao Zedong linked sports with the anti-Japanese movement and served as an important task to serve the democratic war of resistance. With the continuous deepening of revolutionary practice and development, Mao Zedong further defined the development of mass sports, enhance people's physical ideology. When discussing the CPC's cultural and educational policy during the War of Resistance Against Japanese Aggression, Mao Zedong clearly stated that it is necessary to extensively develop the mass sports and fundamentally change the past educational policies and educational systems so that all people will gradually leave ignorant and unhealthy conditions. In the course of sports practice, we can see from the Revolutionary Memorial Museum of photography, a picture of Chairman Mao in table tennis after dinner, composed of two simple flat wood composition, in addition to flatten, push smooth, without any paint, The same is true of table tennis. A Democrat came to Yenan. When he was warmly received by Chairman Mao, the lunch was served by the President's own beans and tomatoes (Yang Jialing's small vegetable plot). At that time, the Democrats said with deep emotion The phrase "China's future depends on Yan'an." Therefore, we can see that sport is more formal, that is, sports itself, sports and labor, military practice closely.

Commander-in-Chief Zhu De pointed out that "To support the anti-fascist war and the arduous struggle of the heavy revolution, not only to arm our minds, but also armed our skill." "Sound spirit, sound in the body" Tell us that every national should have a strong physique, can only take on heavy anti-Japanese founding work, the establishment of a strong free and happy new China ${ }^{[2]}$. Zhu De proposed: "to improve the physical strength of our military, we should proceed in two ways, one is to improve the lives of the military and civilian, to enrich the supply of military and civilian; the second is both universal sports and health care knowledge" (main sports activities climbing, running, basketball, volleyball , Football game ${ }^{[3]}$ ). In Yan'an amateur sports activities, the largest number of participants for the ball, the most popular basketball, Zhu De, commander in chief is the basketball lovers, he often played basketball with the soldiers, which was at the time for the story ${ }^{[4]}$. Snow in the "West", a book also talked about the commander in chief Zhu De often and the soldiers play 
basketball ${ }^{[5]}$. In the difficult revolutionary environment, Commander-in-Chief Zhu personally participated in various mass sports activities from ideology and practice and set an example by himself, which effectively guided the development of mass sports.

He Long called on the army to actively carry out sports activities, improve the body to improve combat effectiveness, better play in Japan, clearly put forward the "sports, to defeat the fascist service" slogan. And in early 1938 set up China's first " Battle basketball team. "He believes that sports, the game can contact the relationship between the army and the people, the relationship between the army and the army; also is" for the revolution and play, to exercise strong and strong iron-like physique, We can better adapt to a variety of hard fighting environment; but also to cultivate a proactive, brave and tenacious, hard-working, disciplined and flexible maneuver fighting style, improve the combat effectiveness of the troops, better serve the victory of the War of Resistance Against Japan [6] ".1942 Chairman Mao also personally met a two O division battle basketball team, and praised the" under the leadership of the leadership of the division in the production, in very difficult conditions to carry out sports, this is very good ${ }^{[7]}$ In September of the same year in September, "Yan'an Daily" published on the Long "militarization of sports," the inscription, so that the soldiers set off a winter swimming craze.In 1945, Long personally founded and established the He Long middle school, its teaching content To the revolutionary war service.He Long to find the correct path of leadership of the Communist Party of China, put forward the "sports for the revolutionary war service" slogan, initially formed a sports ideology of the target, from theory to form have very high The value of the victory for the revolutionary war to play the great power of the people's sports.

\section{The history of mass sports in Yan'an period}

In 1935 October, the Central Red Army arrived in northern Shaanxi Wuqi town, began a new chapter in Yanan period of mass sports. In this period, Yan'an mass sports development can be divided into three stages:

The first phase of 1935 to 1936 (the second Revolutionary War) that is the embryonic stage.

This stage, in the ideology, organization, content inherited the results of mass sports in the Soviet Area. For example: "the iron and steel workers and peasants exercise class, overcome all enemies." ${ }^{[1]}$ "The development of red sports, to develop the unity of the masses of workers and peasants and strong physical." ${ }^{[2]}$; various sports regulations, such as " Sports rules "," less team games "and so on. These thoughts and rules for Yanan period mass sports development began, made full preparations. At this time the party Central Committee began to take various measures to promote the development of mass sports. This period of mass sports is mainly to fight the fire, horse racing, yangko dance, swing, outing, kite flying, tug of war, climbing, playing, playing water, playing drums, climbing.

The second stage:1937 to 1945 (the War of Resistance Against Japan) thrive.

During the war of resistance against Japan, mass sports under the leadership of the Communist Party of China, development than ever before. At the juncture of the national and national life and death, the mass sports has been mentioned to revitalize the nation and defend the country's height and receive great attention. The entire Yan'an presents a kind of, up and down the same, the military and civilian, leadership and the masses to learn together, common entertainment, to participate in sports activities of unity, tension, lively new atmosphere. Yan'an sports activities continue throughout the year, spring and autumn to engage in ball games, there is no conditions for themselves to create such as volleyball, basketball, tennis and so on. Summer use of Yanhe natural swimming pool, engage in swimming, water polo competition and diving exhibition. Winter, engage in skating, figure skating, ice hockey and hunting and other activities. At that time the most famous, in August 1942 the establishment of Yan'an flying fish swimming group, extensive swimming activities carried out to improve the level of swimming also provides a convenient military training.

The third phase 1946-1948 (the third Revolutionary War) mature period.

During the war of liberation, mass sports in Yanan period had a new leap, and mass sports began 
to evolve into new sports form --- socialist sports. Mass sports has created and accumulated a wealth of experience for the new China after the establishment of socialist sports construction and growth laid a solid foundation. With the development of the revolutionary situation, the new liberated areas have been expanding. This period of the Shaanxi-Gansu-Ningxia Border Region economy has made great progress, such as: food, vegetables, cattle and sheep and other strategic materials increasingly abundant for the further development of mass sports laid a solid material foundation. At the same time, the mode of mass sports organization has been gradually matured. The project of mass sports in border area is rich and colorful. It has the characteristics of popularization and tradition, such as basketball, chess, martial arts, game, wrestling, wrist, tug of war, Sandbags, horse racing and so on. Project in addition to the above, the northern Shaanxi counties have their own yangko dance teams, community fire, festivals and celebrations, yangko dance, drums, community fire has become a universal activity of men and women, these activities constitute the Yan'an Mass Sports Of the beautiful landscape.

\section{References}

[1] Selected Works of Mao Zedong: Volume 2 [M]. Beijing: People's Publishing House, 1991: 698.

[2] Commander-in-Chief of the Communist Party of China (CPC) and other leaders of the Chinese People's Liberation Army [PLA] held the opening ceremony of the Games to welcome the representatives of the anti-Japanese base areas and friendly military areas to Yenan [N]. Liberation Daily, 1942-6-21 (2).

[3] Zhu De. I wish the September Sports Conference [N]. Liberation Daily, 1942-9-2 (1).

[4] Zhang Yuan. Yanan life sports fragment [J]. Letter sports, 1957, (7).

[5] Egard Snow. Westbound [M]. Beijing: Foreign Language Teaching and Research Press, 2005.472-580.

[6]"Miss the beloved Chairman Zhu De and Chen Yi He Long comrades"[M].People's Sports Publishing House, 1977,340.

[7] "He Long Chuan" write group. He Long Chuan [M]. Contemporary China Publishing House, 2007,348.

[8] Wu Shaozu.People's Republic of China Sports History (1949-1998) [M]. Beijing: China Book Publishing House, 1999: 11- 13.

[9] Xijie.Shaanxi-Gansu-Ningxia Border Area of the contents and characteristics of folk sports [J] Sports and Literature, 1992 (5): 47.

[10] Western Sports Literature and History Working Committee. Shan - Gan - Ning Border Area Sports Historical Data [Z]. 1986: 48-49.

[11] on Ling. Yanan small physical education [Z]. Shaanxi sports historical data, 1986 (7): 54-55.

[12] Zhao Feng. Border children in battle [N]. Xinhua Daily, 1939-1-4 (4).

[13] Shaanxi Provincial Committee of Sports Literature and History. Shan - Gan - Ning Border Area Sports Historical Data [Z]. 1986: 49.

[14] Shaanxi-Gansu-Ningxia Border Region Education Materials Education Policy Education Policy [M]. Beijing: Educational Science Press, 1981: 309.

[15] "May 17 Ren Bishi on April 14 outline of the report and to add"; the CPC Central Committee Literature Research Institute: "Ren Bishi Chronicle (1904-1950)", Central Literature Publishing House, 2004 edition, paragraph 370 .

[16] Lu Xiqian, Li Zhongquan editor: "Shaanxi-Gansu-Ningxia Border Area Medical and Health History", Shaanxi People's Publishing House, 1994 edition,.

[17] Ou yang Jing: Memories of the health work of the Shaanxi-Gansu-Ningxia Border Region (on), contained in the "Hospital Management", 1984 No. 1.

[18] The five provinces and autonomous regions in Northwest China compilation of the leading group, the Central Archives: "Shaanxi-Gansu-Ningxia border anti-Japanese democratic base" literature volume, the Communist Party of China Historical Materials Publishing House, 1990. 